\title{
Infrared measurements of heat transfer in jet impingement on concave wall applied to anti-icing
}

\author{
by M. Marchand, V. Ménard, J.G. Galier, P. Reulet and P. Millan
}

ONERA Toulouse, Département Modèles pour l'Aérodynamique et l'Energétique,

2 Avenue E. Belin , BP 4025, 31055 Toulouse Cedex 4,

E-mail: Muriel.Marchand@onecert.fr

\begin{abstract}
This paper addresses the experimental study of hot jets impingement on a concave wall. Both low and high Mach number conditions have been investigated. Infrared thermography is used to measure the wall temperature evolution during the heating. This temperature mapping provides the boundary condition necessary to solve the transient heat equation in the wall. From this, heat transfer and Nusselt number are derived and their behaviour compared to literature on the subject when possible. Finally, a correlation of Nusselt versus Reynolds, Prandtl and the nozzle to wall distance is proposed.
\end{abstract}

\section{Introduction}

In order to prevent the airplane performances reduction caused by ice particles entering the engine during the flight, some small anti-icing impinging jets of hot air taken from the combustion chamber are commonly designed. Due to the engine geometry, the hot jets impact on a concave wall. This study is justified by the fact that few literature exists on the subject, at least for high Mach number conditions. Moreover, in order to get experimental results accounting for the complexity of the real configuration, one has to reproduce as far as possible the design of the industrial injection system.

A preliminary bibliographical analysis $[1,11]$ has pointed out the relevant parameters governing the heat transfer in jet impingement for experimental devices presenting some similarities with the present configuration. Although the effects of the Reynolds or Prandtl numbers have been well documented, other parameters, such as the distance between the nozzles and the impact wall, the wall curvature or the Mach number have to be investigated. The study has then been divided in two parts: in a first step, low Mach number have been studied in order to compare with the literature on the subject. Then, the study has been carried out in the real industrial configuration, with Mach numbers about 0.9 .

The present paper is hinged as follows: chapter 2 presents the experimental set-up including the two injection systems (low and high Mach number) and the measurement means. Chapter 3 presents the results and a short discussion. Then a brief conclusion and future prospects end the manuscript.

\section{Experimental set-up}

An overview of the experimental set-up is presented in Figure 1. The test section is made up a round pipe of diameter $100 \mathrm{~mm}$ providing air at flow rates ranging from 0.15 to $3 \mathrm{~kg} / \mathrm{s}$ at a generating pressure of 10 bar. The air can be heated before entering the test section by means of a $570 \mathrm{~kW}$ electric heater. A system of manual and control valves ensure the required flow rate. Two sensors record the flow pressure and temperature.

The test section length (several tens of pipe diameter) has been designed to ensure the flow stability. The injection system is mounted on a diffuser. Moreover, a row of honeycombs breaks the large eddies, ensuring by this way a low turbulence level in the inlet of the injection system. 
Two injectors have been tested: the first one is made up of 9 nozzles, $6 \mathrm{~mm}$ in diameter and the second one consists of 29 nozzles, $2 \mathrm{~mm}$ in diameter (Figure 2). The nozzles are drilled inside the injector wall (stainless steel of thickness $2 \mathrm{~mm}$ ) leading to the "rectangular shaped nozzle".

The impact wall is a $2 \mathrm{~mm}$ thick concave plate made either of steel for the thermal study or of plexiglass for the preliminary aerodynamic study using PIV. In the case of the steel plate, the side boundaries are insulated by a thick layer of rockwool to prevent thermal losses. The overall view of the injection and impact system is represented in Figure 3.

During the tests, either cold or hot air is driven through the nozzles to impinge on the concave wall. The distance between the nozzle exit and the wall can range from 1 to 5 nozzle diameter ( $\mathrm{H} / \mathrm{d}=1$ to 5$)$.

Concerning the measurement means, for the preliminary dynamic study, hot film anemometry and PIV have been used. For the thermal study, thermocouples and infrared thermography provide the temperature conditions required for the heat flux calculation.

An infrared camera is used to provide temperature mapping of the outer surface of the concave wall during the heating (see Figure 3). The wall is supposed to be thin, hypothesis well justified by the low Biot number of the system (low thickness, high thermal conductivity...). The wall outer temperature (convex side) is then representative of the temperature in the impingement region (concave side).

This boundary condition is used to solve the transient heat equation in the plate. From this, maps of convective flux , convective heat transfer rate or Nusselt number are derived.

\section{Results}

A first pre-study has been carried out by using the 9 nozzles- $6 \mathrm{~mm}$ in diameter injector. This set-up provides low Mach numbers $(M<0.2)$ and two values of the nozzle diameter based Reynolds number (7500 and 20400) similar to the experimental literature on the subject. 1D hot film anemometry has first been used to set the free jets axial velocity at the nozzle outlet. Traverse explorations have then been made providing the axial instantaneous velocity of the nine jets. The results indicate a good traverse stability with a deviation of less than $2 \%$ in the flow exit velocity.

Then the mean axial velocity has been measured inside and downstream the potential core region for the central jet. The results indicate a reduced length of this region (1 to 1.5 nozzle diameter) compared to the free jet theory. This is easily explained by the rectangular-shaped nozzle geometry [1] and also by the interaction between the jets [2].

The thermal study has then been carried out. At time $t=0$, the jets heated up to $80^{\circ} \mathrm{C}$ impinge on the concave wall. The infrared camera stores the transient wall outside temperature evolution during the heating. Following the procedure presented in chapter 2 , one can then derive convective heat flux maps. An example is shown in Figure 4 for $\mathrm{H} / \mathrm{d}=1.5$ and $\mathrm{t}=2.88 \mathrm{~s}$ for the 3 central jets. The results indicate that the Nusselt value is maximum in the stagnation region, in agreement with [3]. The comparison between the two values of the Reynolds number (not shown) also indicates that the Nusselt increases with the Reynolds number which is coherent with $[3,4]$. Notice anyway that the radial secondary peak of $\mathrm{Nu}$ for $\mathrm{H} / \mathrm{d}$ corresponding to the potential core and predicted by [5] is not observed but this could be linked to the reduced extent of this region in the present study. From these maps, traverse profiles of Nusselt can be plotted in order to get the nozzle to wall distance $\mathrm{H} / \mathrm{d}$ influence. The comparison indicates that the maximum heat transfer occurs for a value of $\mathrm{H} / \mathrm{d}$ corresponding to the end of the potential core, in agreement with [6]. The Nusselt evolution versus $\mathrm{H} / \mathrm{d}$ is also in good agreement with the correlation proposed by [7]. In this study, indeed, the impact wall curvature effects are taken into account.

Two values of the jet pitch have also been investigated ( $p / d=5$ and $p / d=10)$, not leading to significant discrepancies between the results. 
The second part of the study has then been carried out on the 29 nozzles- $2 \mathrm{~mm}$ in diameter injector (Figure 2). The flow conditions are then a nozzle diameter based Reynolds number of about 35000 and a Mach number of about 0.9 .

After checking the traverse flow uniformity by hot film anemometry, PIV measurements have been made, not reported herein. For more details see [8].

The main results indicate that the jets instantaneous axial velocity is in good agreement with hot film anemometry. The reverse flow regions are also well pointed out. The length of the potential core is in agreement with the previous study at low Mach number.

Concerning the thermal study, 7 nozzle to plate distances $\mathrm{H} / \mathrm{d}$ have been investigated. The air is heated at $80^{\circ} \mathrm{C}$. The identification procedure is the one described in chapter 2 and already used. An example of Nusselt number map is presented in figure 5 for $\mathrm{H} / \mathrm{d}=5$ at time $\mathrm{t}=0.08 \mathrm{~s}$. The results show that the heat transfer is maximum in the stagnation region of the central jet in agreement with [9]. The maximum value of $\mathrm{Nu}$ is about 100 for a $\mathrm{Re}=35000$. Compared to the value obtained for the previous study at $\mathrm{Re}=20400$ $\left(\mathrm{Nu}_{\max }=80\right)$ this seems to confirm the strong influence of the Reynolds number. The influence of the Mach number on the maximum Nusselt value at the stagnation point is not highlighted. But anyway its influence can be noticed on the behaviour of the Nusselt number versus $\mathrm{H} / \mathrm{d}$ by deriving traverse profiles of Nusselt (see for instance Figure 6 showing a comparison of Nu for different nozzle to plate distances). Figure 6 indicates that the heat transfer increases for an increasing value of $\mathrm{H} / \mathrm{d}$. This is in contradiction with the results of the preliminary study and could be explained by the high Mach number effects. Notice anyway that various behaviours of $\mathrm{Nu}$ versus $\mathrm{H} / \mathrm{d}$ are reported in the literature [6, 10].

Another difference with the low Mach number study is that for low values of the nozzle to plate distance $(\mathrm{H} / \mathrm{d}=3)$ a second Nusselt peak is observed. This has already been noticed by [5]

Concerning the evolution of Nusselt at the stagnation point $\mathrm{Nu}_{0}$ versus $\mathrm{Re}$, our results are in good agreement with the correlations proposed by [7 and 11]. Its evolution versus $\mathrm{H} / \mathrm{d}$ can also be represented by a correlation proposed hereafter:

$$
N u_{0}=0.736 \operatorname{Pr}^{0.4} \operatorname{Re}^{0.55}\left(\frac{H}{d}\right)^{0.12}\left(\frac{l}{d}\right)^{-0.09}
$$

Notice that the exponents of $\operatorname{Pr}, \operatorname{Re}$ and $\mathrm{I} / \mathrm{d}$ are not calculated but deduced from [7] and [11]. The exponent for $\mathrm{H} / \mathrm{d}$ is derived from the present experimental results.

\section{Conclusions}

Two experimental set-ups have been studied in details in order to quantify the heat transfer in jet impingement on concave wall either in low or high Mach number conditions. The results highlight the influence of the settling conditions: at low Mach number the heat transfer is maximum for a nozzle to wall distance corresponding to the end of the potential core whereas at high Mach number the heat transfer increases with this parameter. The physics of the phenomena can be explained by the infrared measurements as well as by a PIV campaign not reported here.

A correlation has been derived from the study proposing a new exponent to take into account for the influence of the nozzle to wall distance on the stagnation point Nusselt number evolution. Future prospects of the study are to derive new correlations valid for an extended domain of Reynolds and Mach number. 


\section{References}

[1] Yang, G., Choi, M., Lee, J.S. "An experimental study of slot jet impingement cooling on concave surface: effect of nozzle configuration and curvature", International Journal of Heat and Mass Transfer, Vol. 42, N 12, pp. 2199-2209, 1999.

[2] Chang, C.T. Kojasoy, G. Landis, F., Downing, S., "Confined single and multiple jet impingement heat transfer - Turbulent submerged liquid jets", International Journal of Heat and Mass Transfer, Vol. 38, № 5, pp. 833-842, 1995.

[3] Mohanty, A.K., Tawfek, A.A. "Heat transfer due to a round jet impinging normal to a flat surface", Journal of heat Transfer, Vol. 36, № 6, pp. 1639-1647, 1993.

[4] Gardon, R. Akfirat, J.C., "The role of turbulence in determining the heat transfer characteristics of impinging jets", International Journal of Heat and Mass Transfer, Vol. 8, N 10, pp. 1261-1272, 1965.

[5] Baughn, J.W., Shimizu, S., "Heat transfer measurements from a surface with uniform heat flux and an impinging jet", Journal of Heat Transfer, Vol. 111, № 4, pp. 1096-1098, 1989.

[6] Downs, S.J., James, E. H., "Jet impingement heat transfer - a literature survey", ASME 87-HT-35, pp. 1-11, 1987.

[7] Hrycak, P., "Heat transfer from a row of impinging jets to concave cylindrical surfaces", International Journal of Heat and Mass Transfer, Vol. 24, N 3, pp. 407419, 1981.

[8] Ménard, V. "Etude aérothermique de l'impact de jets sur une surface concave", 2002, Internal report.

[9] Pan, Y. Webb, B. W., 1995, "Heat transfer characteristic of arrays of free surface liquid jets", Journal of heat transfer, vol.117, pp 878-883, 1995.

[10] Goldstein J.F., Timmers, International journal of heat and mass transfer, vol.12 pp1857-1868, 1992.

[11] Garimella, S. V., Rice, R. A. "Confined and submerged liquid jet impingement heat transfer", Journal of Heat Transfer, Vol. 117, № 4, pp. 871-877, 1995.

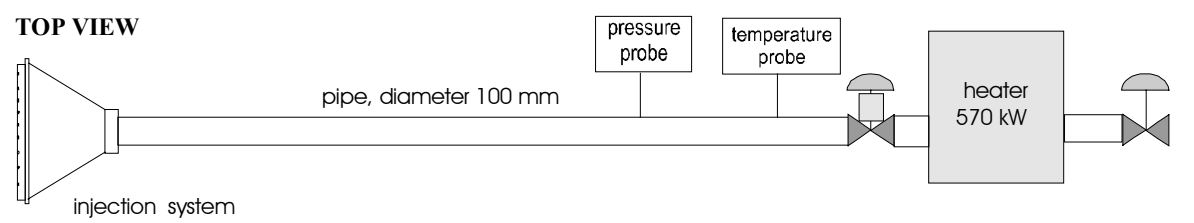

Fig. 1. Experimental Set-up 
9 nozzles Ř $6 \mathrm{~mm}$

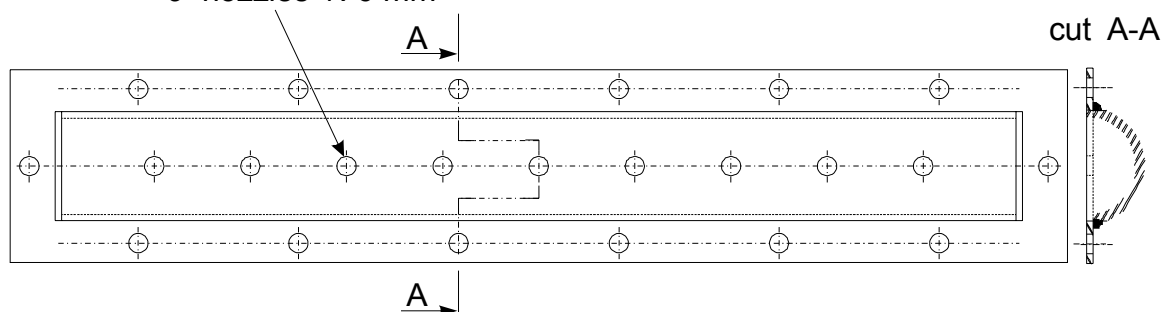

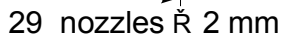

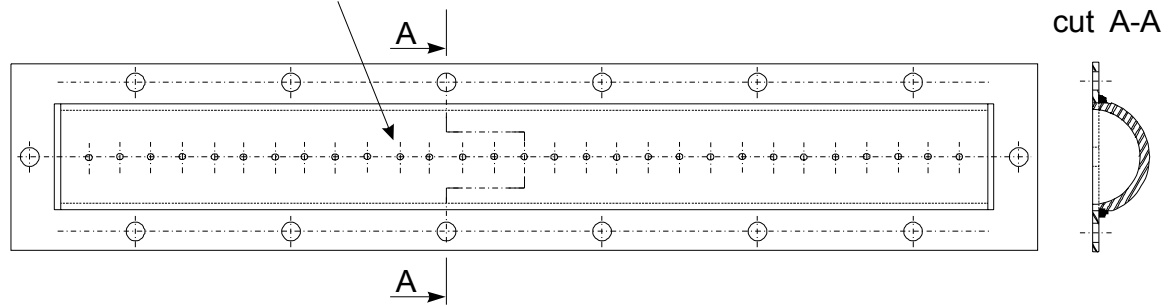

Fig. 2. Injection systems

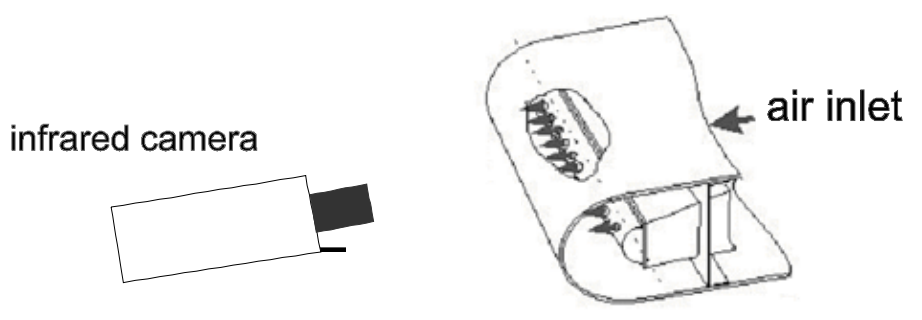

Fig. 3. Infrared Set-up

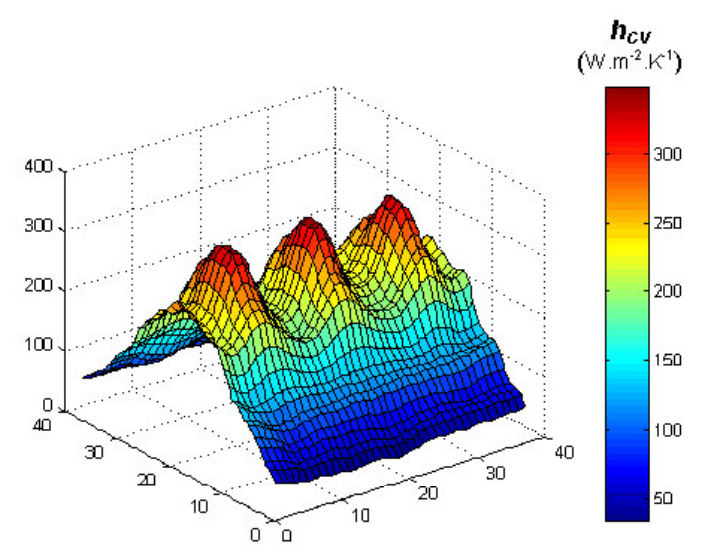

Fig. 4. Nusselt number map for $U_{o}=70 \mathrm{~m} / \mathrm{s}, H / d=1.5, t=2.88 \mathrm{~s}$ 
http://dx.doi.org/10.21611/qirt.2002.017

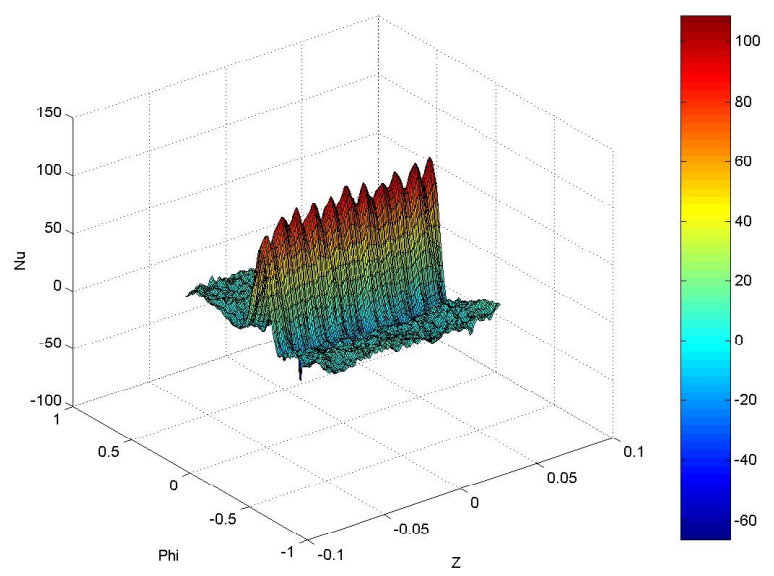

Fig. 5. Nusselt number map for $U o=325 \mathrm{~m} / \mathrm{s}, 29$ jets, $H / d=5, t=0.08 \mathrm{~s}$

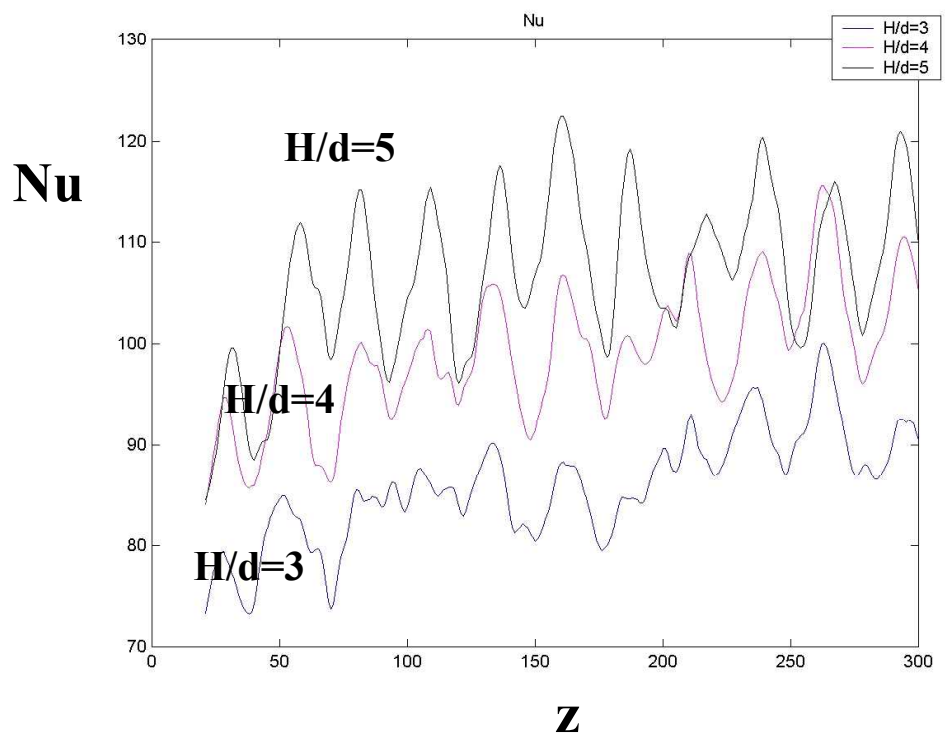

Fig. 6. Nusselt number profiles comparison 